\title{
Study of Oral Cavity Neoplasms
}

\author{
Dr. Reena Vare ${ }^{1}$, Dr. Anil $\operatorname{Vare}^{2}$, Dr. Arjun Antony ${ }^{3}$ \\ ${ }^{1}$ Professor, ENT, MGM Medical College, Aurangabad \\ ${ }^{2}$ Associate Professor, Pathology, MGM Medical College, Aurangabad \\ ${ }^{3}$ Chief Resident, ENT, MGM Medical College, Aurangabad
}

\begin{abstract}
Aim: To study the incidence, etiology and types of various oral cavity neoplasmsclinicopathologically. Methods: The study was carried out at primary level center from November 2010 to October 2012. In this study 582 patients were screened, out of which 66 patients who fulfilled the inclusion and exclusion criteria were included in the study. Results: $86 \%$ of all neoplasms were squamous cell carcinoma, out of which $84 \%$ were grade -1 , which responded very well to surgery and radiotherapy.Conclusion: $92 \%$ of patients were having tobacco addiction.
\end{abstract}

Keywords: Squamous, oral neoplasm, tobacco, tongue, buccal

\section{Introduction}

The oral cavity extents from the lips to the palatoglossal folds. The space bordered by the teeth \&gingivaeis the oral cavity proper. It is bounded inferiorly by the floor of the mouth and tongue and superiorly by the hard palate. The buccal mucosa extentsfrom the commissure of the lips anteriorly to the palatoglossal fold posteriorly. It is lined by thick non-keratinized stratified squamous epithelium. The gingival mucosa surrounds the neck of teeth and alveolar mucosa overlies the alveolar bone and extents to the vestibular reflections. Both of which are non-keratinized stratified squamous epithelium.

The hard palate is continuous anteriorly with the maxillary alveolar arches and posteriorly with the soft palate. Most of the palatal mucosa is firmly bound to the underlying bone forming a mucoperiosteum. It is covered by orthokeratinized stratified epithelium and posteriorly contains many minor mucoussalivary glands.

The oral part of the tongue (anterior two third) lies in front of the V-shaped sulcus terminalis. It is mobile and attached to the floor of the mouth anteriorly by a median lingual frenulum. The dorsal part is covered bystratified squamous epithelium and contains several types of papillae. The most numerous are the hair like filiform papillae whichare heavily keratinized. The ventrum of the tongue is covered by thin, non-keratinized stratified squamous epithelium which is continuous with similar mucosa in the floor of the mouth.

The floor of the mouth is a horseshoeshaped area between the ventrum of the tongue medially and the gingivae of the lower teeth anteriorly and laterally. It extends to the palatoglossal folds distally and is in continuity with the retromolar pad behind the third molar tooth. This region forms only about $20 \%$ of the total mucosal area.

\section{Material and Methods}

The study was carried out in the Department of E.N.T. at MGM Medical college, Aurangabad from November 2010 to October2012. In this study of two years, 582 patients were screened, out of which 66 patients who fulfilled the inclusion and exclusion criteria were included in the study. Histopathological examination was done in all cases.Source of data were patients who presented in outpatient and inpatient department of E.N.T. of M.G.M. Medical college, Aurangabad. Inclusion criteria was patient of all age groups and of either sex (male or female ) who presented with Ulcers, growth,patch over mucosa of oral cavity.

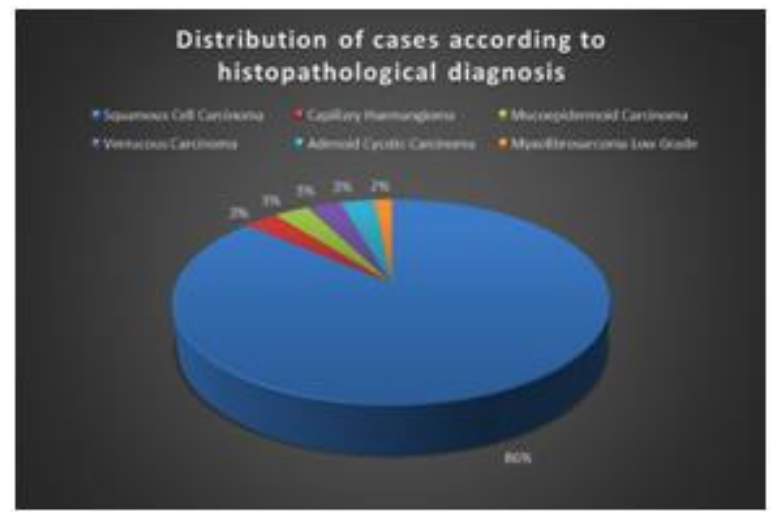

Figure 1: Distribution of cases according to histopathological diagnosis

Exclusion criteria was neoplasm of salivary glands, oropharynx and posterior one third of tongue. Adetailed history, proper oral cavity examination and neck examination were carried out by the otolaryngologist. The patients were informed about the procedure and written consent was obtained from the patients before subjecting them to surgical procedure (Biopsy, FNAC) and histopathological examination.

Equipment required included E.N.T. examination set up with biopsy forceps and trucut needles along with microtome, staining material and microscope.

Result: In total of 582 patients of oral pathology only 66 patients showed neoplasm of oral cavity. The incidence of oral cavity neoplasm in present study was $11.34 \%$. Highest number of cases were seen in age group of 41-50 


\section{International Journal of Science and Research (IJSR) \\ ISSN (Online): 2319-7064 \\ Index Copernicus Value (2013): 6.14 | Impact Factor (2015): 6.391}

years $(30 \%)$. The most common site of neoplasm was of tongue $(48.5 \%)$ followed bybuccal mucosa $(21 \%)$.

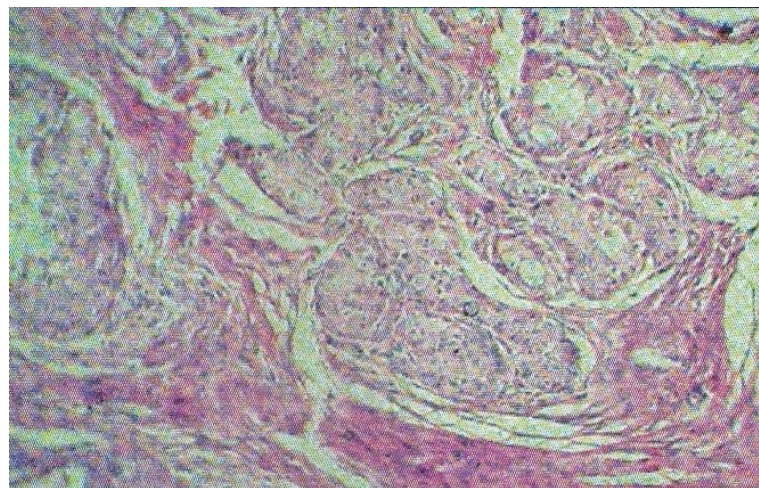

Figure 2: Photomicrograph of mucoepidermoid carcinoma showing tumour consisting of squamous, mucus and clear cells arranged in sheets and nests (H\&E-10X)

In total of 66 cases, $86 \%$ were Squamous cell carcinoma, $3 \%$ were capillary neoplasm, $3 \%$ were mucoepidermoid carcinoma, 3\% were verrucous carcinoma, 3\% were adenoid cystic carcinoma and $2 \%$ were low grade myxofibrosarcoma.

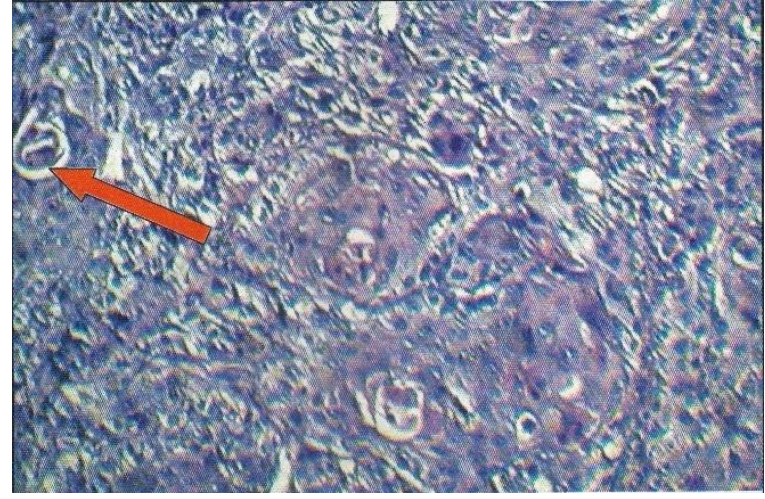

Figure 3: Photomicrograph of squamous cell carcinoma showing tumour consisting of round to polygonal cells with hyperchromatic pleomorphic nuclei arranged in groups along with keratin pearls (arrow) (H\&E - 10X)

\section{Discussion}

Cancer is a generic term for a large group of diseases that can affect any part of the body.

3.1 Table 1- Distribution of cases according to site of squamous cell carcinoma

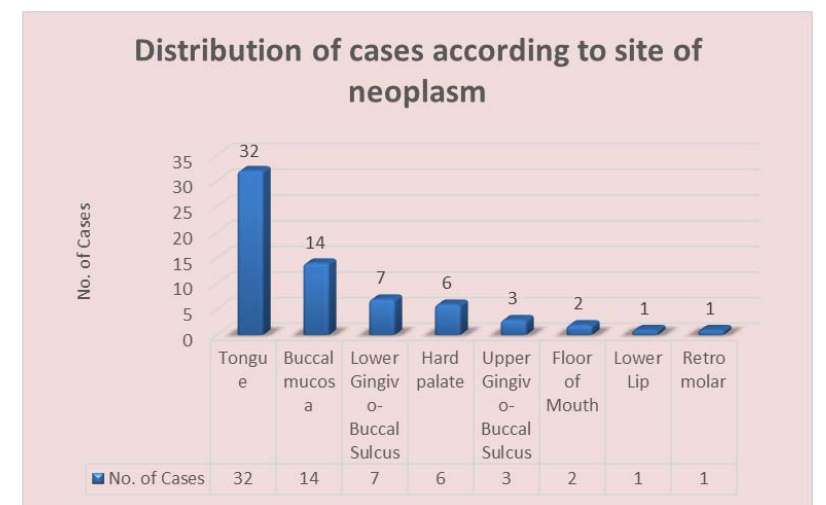

Other termsused are neoplasm and tumour. Cancer is a leading cause of death worldwide and accounted for 7.6 million deaths (around 13\% of all deaths).

3.2 Table 2 - Distribution of cases according to associated risk factors

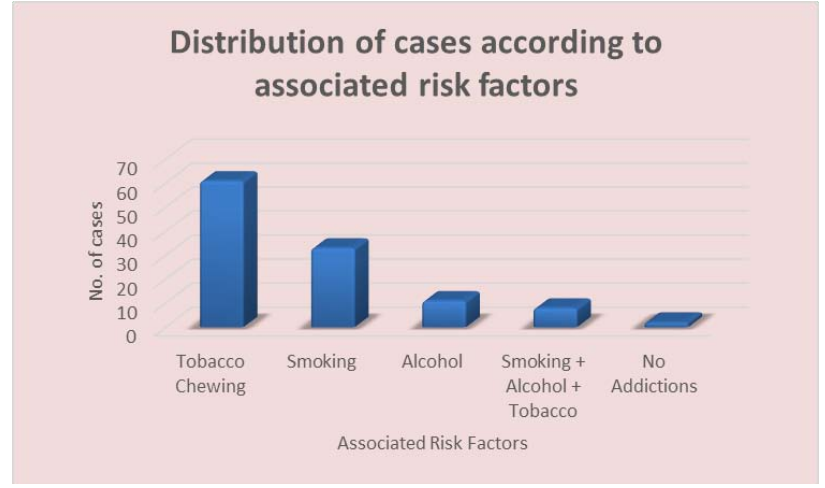

Oral cancer is the sixth most common cancer in the world ranking eight in the developed countries and third in the developing countries. India has one of the highest incidence of oral cancer in the world (12.6 per 1,00,000 population). The world health organization (WHO) reported oral cancer as having high mortality ratio. The term oral cancer (OC) includes a diversity of neoplasms arising from oral cavity. The term oral cavity refers to lips, buccal mucosa, alveolar ridges,retromolartrigone, hard palate, floor of the mouth and anterior two thirds of the tongue. Typically it occurs in the $5^{\text {th }}$ to $8^{\text {th }}$ decade of life. Squamous cell carcinoma is the most common malignant neoplasm of the oral cavity. The aetiology of $\mathrm{OC}$ is multifactorial. Genetic, environment, social and behavioural effects all may be implicated. The consumption of tobacco andalcohol is closely associated not only with the development of OC,butalso with the course of the disease .Tobacco and alcohol consumption is associated with poor prognosis. Tobacco in differentforms such as chewing,snuff dipping, cigarette, cigar, pipe smoking is associated with an increase incidence of oral cancer.Tobacco when used in combination with betel nut leaf and slaked lime or alcohol increasesrate of oral cancer markedly. The incidence of oral cancer isvariable in different parts of India due to variation in abuse habits which are also influenced by different cultures and customs. Cancers of the oral cavity largely consist of primary squamous cell carcinoma $(80 \%-$ $90 \%$ ) arising from the mucosal lining.

\section{Conclusion}

- The incidence of oral cavity neoplasm in the present study was $11.34 \%$

- Most cases (30\%) belonged to fifth decade of life (41 - $50 \mathrm{yrs}$ ), the mean age of the cases was $48.8 \mathrm{yrs}$ with mean age for males was 45.6 yrs and for females 55.7 yrs.

- Most oral neoplasm cases were males (73\%),even among the individual age groups having male to female ratio of 2:6:1.

- Significant higher proportion of cases $(92 \%)$ had the habit of tobacco chewing (smokeless tobacco) both in males and females as compared to other habits.

\section{Volume 5 Issue 7, July 2016 www.ijsr.net}




\section{International Journal of Science and Research (IJSR) \\ ISSN (Online): 2319-7064}

Index Copernicus Value (2013): 6.14 | Impact Factor (2015): 6.391

- Habits of smoking and alcohol abuse were found only among males

- Majority of cases $(81.8 \%)$ reported to the hospital within 1 - 3 monthsof onset of oral neoplasm related signs and symptoms.

- Growth in the oral cavity (37\%) followed by ulcer (33\%) was the commonest presentation.

- Most cases (48.5\%) had neoplasm of tongue followed by cases with neoplasm ofbuccal mucosa $(21 \%)$.

- Among cases with neoplasm of tongue, there was higher proportion of males compared to females.

- Among cases with neoplasm of buccal mucosa,hardpalate, upper and lower gingivo-buccal sulcus. There were higher proportion of females compared to males.

- Most cases (71.2\%) had squamous cell carcinoma grade-1. In conclusion the squamous cell carcinoma grade -1 was the commonest oral neoplasm found in the present study. Tobacco abuse was the commonest factor. The commonest clinical presentation was ulcer and growth.Tongue was the commonest site.

\section{References}

[1] Petersen, P. E. (2003). The World Oral Health Report 2003: continuous improvement of oral health in the 21st century - the approach of the WHO Global Oral Health Programme. Community Dentistry and Oral Epidemiology, 31, 3-24. doi:10.1046/j..2003.com122.x

[2] Bundgaard, T., Bentzen, S. M., \& Wildt, J. (1994). The prognostic effect of tobacco and alcohol consumption in intra-oral squamous cell carcinoma. European Journal of Cancer. Part B, Oral Oncology, 30B(5), 323-328. doi:10.1016/0964-1955(94)90033-7

[3] Khanolkar, V. R. (1944). Oral Cancer in Bombay, India. A Review of 1,000 Consecutive Cases. Cancer Research, 4(5), 313-319. Retrieved from http://cancerres.aacrjournals.org/content/4/5/313.abstrac $\mathrm{t}$

[4] Paymaster, J. C. (1956). Cancer of the buccal mucosa. A clinical study of 650 cases in Indian patients. Cancer, 9(3), 431-435. doi:10.1002/10970142(195605/06)9:3<431::AIDCNCR2820090302>3.0.CO;2-T

[5] Sankaranarayanan R. Oral cancer in India: An epidemiologic and clinical review. Oral Surg Oral Med Oral Pathol. 1990;69:325-30.

[6] Kayembe, M. K., \& Kalengayi, M. M. (1999). Histological and epidemiological profile of oral cancer in Congo (Zaire). Odonto-Stomatologie Tropicale = Tropical Dental Journal, 22(88), 29-32. Retrieved from http://europepmc.org/abstract/MED/11372124

[7] Iype E M, Pandey M, Mathew A, Thomas G, Sebastian $\mathrm{P}$, Nair M K. Oral cancer among patients under the age of 35 years. J Postgrad Med 2001;47:171

[8] Hashibe, M., Jacob, B. J., Thomas, G., Ramadas, K., Mathew, B., Sankaranarayanan, R., \& Zhang, Z. F. (2016). Socioeconomic status, lifestyle factors and oral premalignant lesions. Oral Oncology, 39(7), 664-671. doi:10.1016/S1368-8375(03)00074-5

[9] Dias GS, Almeida AP. A histological and clinical study on oral cancer: descriptive analyses of 365 cases.Med Oral Patol Oral Cir Bucal. 2007;12:E474-8
[10] Cabral, L. A. G., de Carvalho, L. F. das C. e S., Salgado, J. A. P., Brandão, A. A. H., \& Almeida, J. D. (2010). Gingival Squamous Cell Carcinoma: a Case Report. Journal of Oral \& Maxillofacial Research, 1(3), e6. http://doi.org/10.5037/jomr.2010.1306

[11] Singh, S., Gokkulakrishnan, Jain, J., Pathak, S., \& Singh, K. T. (2010). Adenoid Cystic Carcinoma of Buccal Mucosa. Journal of Maxillofacial \& Oral Surgery, 9(3), 273-276. http://doi.org/10.1007/s12663010-0086-8

[12] Udeabor, S. E., Rana, M., Wegener, G., Gellrich, N.-C., \&Eckardt, A. M. (2012). Squamous cell carcinoma of the oral cavity and the oropharynx in patients less than 40 years of age: a 20-year analysis. Head \& Neck Oncology,4, 28. http://doi.org/10.1186/1758-3284-4-28

\section{Author Profile}

Dr. Reena Vare is Professor, Department of ENT, MGM Medical College, Aurangabad, Maharashtra, India

Dr. Anil Vare is Associate Professor, Department of Pathology, MGM Medical College, Aurangabad, Maharashtra, India

Dr. Arjun Antony is Chief Resident, Department of ENT, MGM Medical College, Aurangabad, Maharashtra, India 